\title{
Temporal abundance of Aedes aegypti in Manaus, Brazil, measured by two trap types for adult mosquitoes
}

\author{
Carolin Marlen Degener ${ }^{1 /+}$, Tatiana Mingote Ferreira de Ázara ${ }^{1}$, Rosemary Aparecida Roque $^{2}$, \\ Cláudia Torres Codeço ${ }^{3}$, Aline Araújo Nobre ${ }^{3}$, Jörg Johannes Ohly ${ }^{4}$, \\ Martin Geier ${ }^{5}$, Álvaro Eduardo Eiras ${ }^{1}$
}

\author{
${ }^{1}$ Laboratório de Ecologia Química de Vetores, Departamento de Parasitologia, Universidade Federal de Minas Gerais, \\ Belo Horizonte, MG, Brasil 'Laboratório de Entomologia Aplicada, Universidade Nilton Lins, Manaus, AM, Brasil \\ ${ }^{3}$ Programa de Computação Científica, Fundação Oswaldo Cruz, Rio de Janeiro, RJ, Brasil ${ }^{4}$ Centro de Estudos dos Trópicos Úmidos, \\ Universidade do Estado do Amazonas, Manaus, AM, Brasil ${ }^{5}$ Biogents AG, Regensburg, Germany
}

\begin{abstract}
A longitudinal study was conducted in Manaus, Brazil, to monitor changes of adult Aedes aegypti (L.) abundance. The objectives were to compare mosquito collections of two trap types, to characterise temporal changes of the mosquito population, to investigate the influence of meteorological variables on mosquito collections and to analyse the association between mosquito collections and dengue incidence. Mosquito monitoring was performed fortnightly using MosquiTRAPs (MQT) and BG-Sentinel (BGS) traps between December 2008-June 2010. The two traps revealed opposing temporal infestation patterns, with highest mosquito collections of MQTs during the dry season and highest collections of BGS during the rainy seasons. Several meteorological variables were significant predictors of mosquito collections in the BGS. The best predictor was the relative humidity, lagged two weeks (in a positive relationship). For MQT, only the number of rainy days in the previous week was significant (in a negative relationship). The correlation between monthly dengue incidence and mosquito abundance in BGS and MQT was moderately positive and negative, respectively. Catches of BGS traps reflected better the dynamic of dengue incidence. The findings help to understand the effects of meteorological variables on mosquito infestation indices of two different traps for adult dengue vectors in Manaus.
\end{abstract}

Key words: Aedes aegypti - MosquiTRAP - BG-Sentinel - surveillance - dengue

Dengue is a major health problem in Brazil, where incidence rates and disease severity have increased during the past decades (Teixeira 2012). Aedes aegypti (L.), the local vector is found in all Brazilian states and since the recent introduction of dengue virus (DENV)-4, all four serotypes of the DENV are circulating in the country (Figueiredo et al. 2008, 2013a, Nogueira \& Eppinghaus 2011, Bastos et al. 2012).

Manaus, the capital of the state of Amazonas was reinvaded by Ae. aegypti in 1996 and the first epidemic occurred in 1998-1999 (Figueiredo et al. 2004). The local equatorial climate (year round high temperature and high humidity, with a short period of less precipitation) offers favourable conditions for dengue vectors. The simultaneous circulation of all four DENV serotypes (Bastos et al. 2012, Figueiredo et al. 2013b) increases the risk of epidemics with high numbers of dengue haemorrhagic fever patients. The infestation of Ae. aegypti and Aedes albopictus (Skuse) was documented in all seasons

doi: 10.1590/0074-0276140234

Financial support: World Bank, CNPq, UEA, FAPEAM, CAPES

$\mathrm{AEE}$ receives scholarships from CNPq.

+ Corresponding author: carolindegener@hotmail.de

Received 30 June 2014

Accepted 11 November 2014 in four neighbourhoods with inhabitants of different socio-economic statuses and urbanisation types (Ríos-Velásquez et al. 2007). Dengue usually follows a seasonal pattern in Manaus, with less cases being reported during the drier months (from June-October).

Various studies have investigated a possible association between meteorological variables and the abundance of dengue vectors (Mogi et al. 1988, Scott et al. 2000, Vezzani et al. 2004, Ríos-Velásquez et al. 2007, Honório et al. 2009, Azil et al. 2010, Barrera et al. 2011). Meteorological variables interact directly with several factors which affect mosquito life quality: egg viability depends on humidity and temperature (Christophers 1960, Farnesi et al. 2009), the presence of some breeding sites depends on rain and the time of larval development and larval survivorship is temperature-dependent (Christophers 1960, Rueda et al. 1990), to name a few. Furthermore, Ae. aegypti's vector efficiency is influenced by temperature (Watts et al. 1987). It is therefore expected, that dengue incidence also depends on meteorological factors. Seasonality of dengue fever has been observed in several settings, including Brazil (Chadee et al. 2007, San Martin et al. 2010, Descloux et al. 2012).

For many years, dengue vector monitoring was based on traditional Stegomyia indices (house index, container index and Breteau index) and derivations of them, which are based on the presence of Aedes larvae in breeding sites. These indices are valuable to evaluate the effect of larval control interventions, but their usefulness for estimating adult vector populations or dengue transmis- 
sion risks is limited (Focks 2003). Furthermore, larval surveys are labour-intensive, time-consuming and the performing field staff has to be highly motivated and experienced to locate breeding sites. Pupal/demographic surveys give a better proxy of adult populations (Focks 2003), but due to the need of a large sample size, they are more labour intensive than larval surveys. Another alternative that has been used for dengue vector monitoring is the ovitrap, a dark recipient filled with a hay infusion that lures gravid mosquitoes (Fay \& Eliason 1966, Reiter et al. 1991). After entering the ovitrap, females land on an oviposition strip and lay eggs. This trap type informs about adult mosquito presence, but as numbers of eggs laid per female are not known, they give no indication of the number of adults that entered the trap.

In adulticidal sticky ovitraps, the oviposition strip is replaced by a sticky card that enables mosquito quantification and identification (Ritchie et al. 2003). The MosquiTRAP (MQT) (Ecovec Ltda, Brazil) is a type of sticky ovitrap. It consists of a black plastic cylinder partially filled with water, a sticky card and a synthetic oviposition attractant (AttrAedes, Ecovec Ltda, Brazil) (Gama et al. 2007, Eiras \& Resende 2009).

The BG-Sentinel (BGS) (Biogents AG, Germany) is a suction trap that attracts female Ae. aegypti of different physiological development phases and males in considerable numbers without the need of adding $\mathrm{CO}_{2}$, outperforming other adult traps which are used with $\mathrm{CO}_{2}$, (Kröckel et al. 2006, Maciel-de-Freitas et al. 2006, Williams et al. 2006, Meeraus et al. 2008).

In recent years, trapping tools for adult mosquitoes, including the MQT and the BGS traps, have been increasingly used to monitor dengue vector abundance (Ritchie et al. 2004, Williams et al. 2007, Eiras \& Resende 2009, Azil et al. 2010, Melo et al. 2012). Correlations between Aedes collections in sticky or BGS traps and dengue transmission have been previously described in Australia, Brazil and Puerto Rico (Ritchie et al. 2004, Barrera et al. 2011, Melo et al. 2012).

Knowledge of associations between Ae. aegypti catches of these traps and meteorological variables is important for the development of models, which predict dengue vector infestation and therefore enable the application of pre-emptive dengue vector control. Longitudinal studies describing associations between $\mathrm{Ae}$. aegypti abundance, measured with one of the above-mentioned traps and meteorological variables, have already been performed in Australia, Puerto Rico and Brazil (Honório et al. 2009, Azil et al. 2010, Barrera et al. 2011). However, the two traps have never been used simultaneously in longitudinal studies.

The objectives of this study were to characterise the temporal abundance of adult Ae. aegypti as measured by BGS and MQT traps to compare trapping indices obtained by the two different traps, to characterise the association between meteorological variables and fortnightly trap catches and to investigate relationships between trap catches and dengue incidence in Manaus.

\section{MATERIALS AND METHODS}

Study area - The study was conducted in Cidade Nova $\left(-3^{\circ} 2{ }^{\prime} 39^{\prime \prime}-59^{\circ} 57^{\prime} 54^{\prime \prime}\right)$, a residential neighbour- hood in the northern zone of Manaus (Fig. 1). Houses in Cidade Nova are mainly made of wood and brick, most of them with verandas and/or backyards. Within the neighbourhood, which had an estimated population of about 121,135 (IBGE 2011), six clusters, defined as areas of 104-151 households, were chosen. Clusters had a minimum distance of $250 \mathrm{~m}$ between each other.

The climate in Manaus is a tropical monsoon climate with an annual daily average temperature of $27^{\circ} \mathrm{C}$, an average annual rainfall of approximately $2,300 \mathrm{~mm}$ and
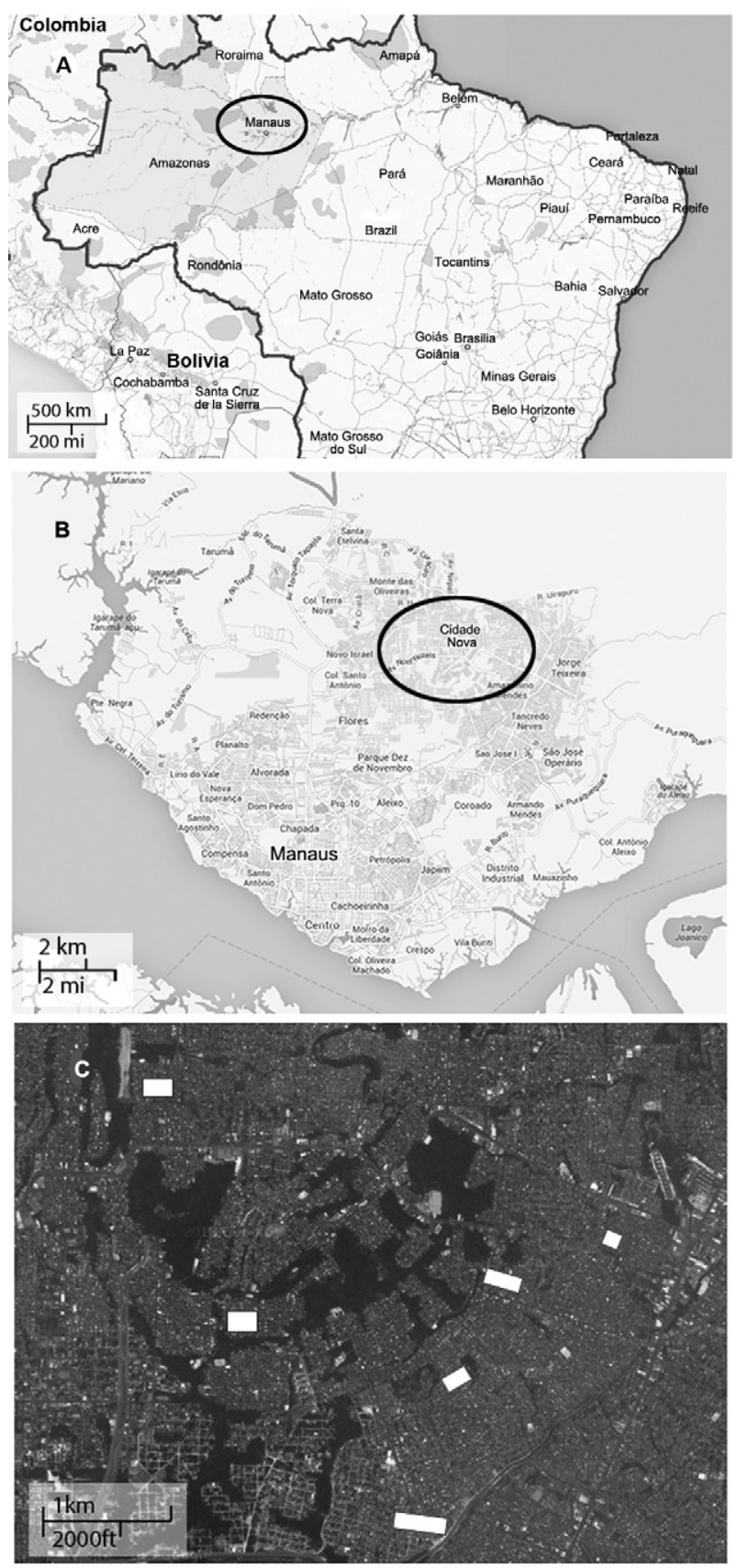

Fig. 1: maps of the study area. A: Brazil with the localisation of Manaus, state of Amazonas, indicated by a black circle; B: the neighbourhood of Cidade Nova, in Manaus, indicated by a black circle; $\mathrm{C}$ : localisation of the six clusters, indicated by white rectangles. 
a mean annual number of 180 rainy days. June-October is the driest period of the year, with total accumulated precipitations lower than $130 \mathrm{~mm}$. Temperature fluctuations throughout the year are low.

Entomological monitoring - Ae aegypti adults were monitored fortnightly in each of the six areas with two different traps, the MQT and the BGS traps from December 2008-June 2010, thus covering two rainy seasons and one dry period.

The MQT lures gravid Ae. aegypti by visual and olfactory stimuli. The AtrAedes enhances the attractiveness (Eiras \& Resende 2009). One sticky trap was installed in four different blocks of each cluster, totalling 24 traps. The traps remained on fixed positions in the peridomestic area of premises, sheltered from direct sun and strong rain. During the fortnightly trap inspections, captured mosquitoes were identified and sexed by trained fieldworkers with the help of a magnifying glass. The obtained data was registered in a mobile phone using software especially developed for this purpose and immediately send to an online database of Ecovec Ltda. One drop of Bacillus thuringiensis var. israelensis (Bt-horus $\mathrm{SC}^{\circledR}$ ) was added to the water in the inferior part of all traps during all trap inspections to avoid development of mosquito larvae.

The BGS lures mosquitoes of different physiological stages by imitating the convection currents of a human body and by using visual and olfactory cues (Kröckel et al. 2006, Maciel-de-Freitas et al. 2006, Ball \& Ritchie 2010). BGS traps (1 trap per house) were installed in the peridomestic area of four non-neighbouring houses in the centre of each cluster. All 24 traps (4 traps in each of the 6 clusters) were installed in the mornings of the same day and removed after a collection period of $24 \mathrm{~h}$. Trap positions (houses) changed with each collection cycle. Trapped mosquitoes were sexed, counted and identified to species for mosquitoes of the genus Aedes and to genus for mosquitoes of other genera. Ae. aegypti females were dissected for the determination of their parity status and classified as either nulliparous or parous (Detinova 1962). Mosquitoes with ovarioles developed past Christopher's stage II were classified as "late ovarian development stages".

Human dengue cases - Confirmed monthly dengue cases in the Cidade Nova were obtained from the Information System of Notifiable Diseases of the State of Amazonas [made available by the Foundation of Health Vigilance of Amazonas (FVS-AM)]. Case confirmation is based on clinical and laboratorial evidence (IgM ELISA, reverse transcription-polymerase chain reactioN, virus isolation or immunohistochemistry) (MS/SVS 2005). Dengue incidence was calculated based on the number of inhabitants of the Cidade Nova (IBGE 2011).

Meteorological data - Daily meteorological data in different categories were obtained from the Brazilian National Meteorological Institute. Mean values for weekly data were calculated: maximum weekly temperature $\left({ }^{\circ} \mathrm{C}\right)($ Tmax $)$, minimum weekly temperature (Tmin), number of rainy days per week (Ndaysrain), accumulated weekly rainfall (Rain), mean weekly relative humidity $(R H)$ and minimum weekly $R H(R H m i n)$. For each of these variables, lagged values were calculated (lags of 1, 2 and 3 weeks, henceforth Rain1w, Tmin2w and so one). Additionally, Ndaysrain and Rain were calculated for sums of lagged values: week $1+$ week 2 , week $1+$ week $2+$ week 3 , week 2 + week 3 (henceforth Rain 1.2w, Rain1.3w, Rain2.3w). As BGS traps had a sampling period of $24 \mathrm{~h}$, variables that referred to each day of BGS sampling were also included in the data set: minimum daily temperature, maximum daily temperature (Tmaxd) and mean daily humidity. These variables were only used for the analysis of BGS data.

Data analysis - To compare overall mean female Ae. aegypti catches per trap type per cluster, values were $\log _{10}(x+1)$-transformed (to meet the assumption of normal distribution) and compared using one-way ANOVA and Tukey's honest significant differences post-hoc test.

Pearson correlation was used to determine correlation between $\log _{10}(\mathrm{x}+1)$ - transformed mean numbers of female Ae. aegypti caught per sampling week per cluster obtained by the two trap types in each of the six clusters.

As the dengue incidence data was only available monthly and as this data did not consider the cluster borders, Pearson correlation was performed based on data of monthly mean catches of Ae. aegypti females in MQT or BGS traps and monthly dengue incidence in Cidade Nova. Monthly variables were $\log _{10}(\mathrm{x}+1)$ - transformed prior to correlation analysis to meet the assumption of normal distribution.

For the analysis of mosquito trapping time series, the mean number of female Ae. aegypti per trap per cluster per trap type per monitoring week (MeanAaefem) was calculated by dividing the sum of Ae. aegypti females collected in each of the six clusters with the number of traps (MQT or BGS) that were used in each cluster in each sampling week. Mean values were $\log _{10}$-transformed $(\mathrm{x}+1)($ henceforth lMeanAaefem) so that the data followed a Gaussian distribution (Zar 2010). First, we used additive mixed models (AMM) to investigate possible nonlinear effects of meteorological variables and of the variable week. In these models, the grouping variable cluster was used as a random factor. For BGS and MQT data, effects were linear, justifying the use of linear mixed effects (LME) models, again with cluster as random factor. As variables of the same meteorological category, but with different lags were highly correlated, only the best predictor for each category was included in an initial full model. Minimal models were selected using stepwise forward/backward selection. As autocorrelation analysis of the LME models' residuals revealed significant autocorrelation at lag 1, an autocorrelation function of first order (AR-1) was added. For the BGS time series, residual spread varied per cluster. The varIdent variance function was therefore added to the model, to allow for heteroscedasticity (Pinheiro \& Bates 2000, Zuur et al. 2009). Only the results of the best models (significance of explanatory variables, lowest Aikaike information criterion values, adequate residual plots, autocorrelation plots and partial autocorrelation plots) are presented.

The statistical software R 2.12.1 (R Development Core Team 2011) was used for data analysis. AMM and LME models were implemented using the libraries mgcv (Wood 2006) and nlme (Pinheiro et al. 2011), respectively. 


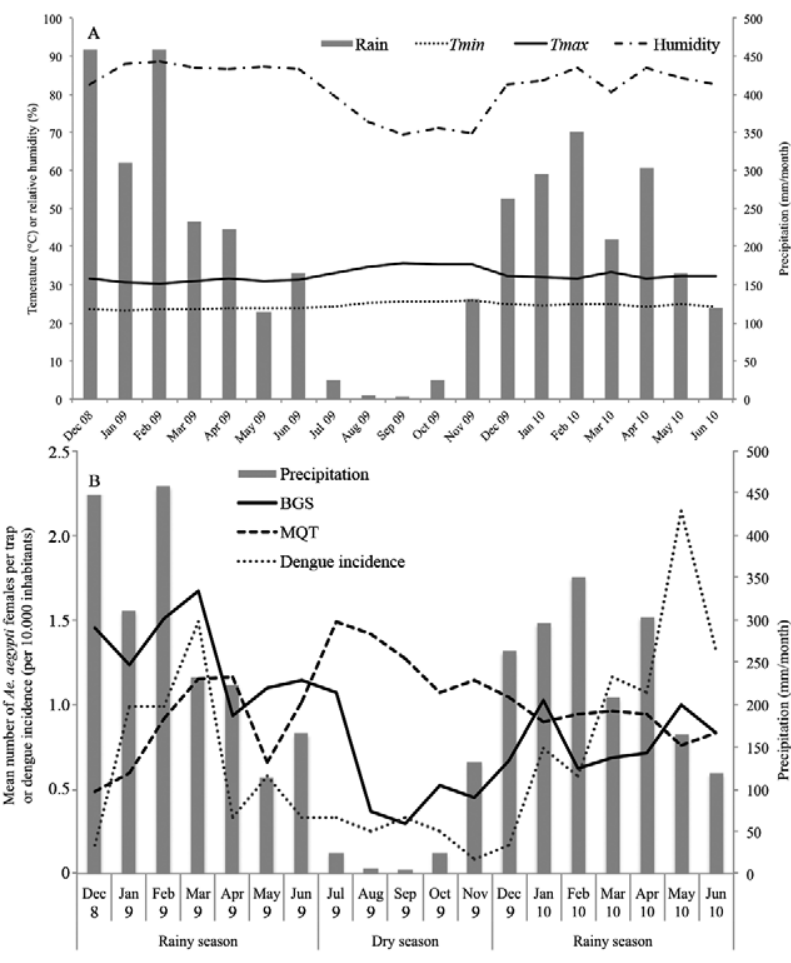

Fig. 2A: monthly precipitation (rain), monthly maximum mean temperature (Tmax), monthly minimum mean temperature (Tmin) and monthly mean relative humidity (humidity) in Manaus, state of Amazonas, Brazil, between December 2008-June 2010; B: monthly precipitation (grey bars), mean monthly catches of female Aedes aegypti in MosquiTRAP (MQT) (dashed line) and BG-Sentinel (BGS) (solid line) and dengue incidence per 10,000 (dotted line) in Manaus between December 2008-June 2010.

Ethics - The study received approval from the Ethical Committee of the Doutor Heitor Vieira Dourado Foundation of Tropical Medicine of Manaus (CAAE: 0013.0.114.000-08).

\section{RESULTS}

Meteorological data - During the study period, minimum and maximum monthly temperature varied between $23.3-25.9^{\circ}$ and $30.3-35.6^{\circ} \mathrm{C}$, respectively (Fig. 2A). High fluctuations were observed for monthly precipitation, which varied between 4.2-458.1 mm/month. From 9 July-9 November, a mean of 3.2 days per month (range 1-5 days) were positive for rainfall whilst during the remaining months a mean of 18.6 days were rainy (range 12-26 days). Relative mean monthly humidity varied between 69.3-88.5\% (Fig. 2A).

Mosquito catches - MQTs collected 3,444 mosquitoes (mean 3.95) (Culex spp, Ae. aegypti and Ae. albopictus) during the whole study period, whilst BGS collected 22,000 mosquitoes (mean 24.23). Both traps captured predominantly Culex spp (mainly Culex quinquefasciatus) in all six areas (Table I). Overall, MQTs collected a mean number ( \pm standard error) of $2.6 \pm 2.9$ Culex spp mosquitoes during two weeks, whilst BGS traps collected 10 times as much (22.6 \pm 45.8$)$ in their shorter collection period of $24 \mathrm{~h}$. Of the total catches, MQTs and BGS collected $66.3 \%$ and
93.4\% Culex spp, respectively. The second-most abundant mosquito species in both trap types was Ae. aegypti, which represented $30.3 \%$ of MQT and $5.9 \%$ of BGS catches. The MQTs were more specific for Ae. aegypti.

Ae. albopictus were rare in both traps. Considering only Ae. aegypti and Ae. albopictus, 89.9\% and 90.2\% were $A$ e. aegypti in MQT and BGS traps, respectively.

Female Ae. aegypti catches from MQTs differed significantly between the six areas $[\mathrm{F}=30.6$; degrees of freedom $(\mathrm{df})=5 ; \mathrm{p}<0.001$, with mean catches per area ranging from 0.13-1.72 individuals per trap per sampling period of two weeks (Table I). Maximum numbers of females collected per trap per sampling period in each cluster varied between two-13. In total, about $83 \%$ of caught Ae. aegypti were females, with values in clusters ranging between $40.9-97.9 \%$ (Table I). In four out of the six clusters, the percentage was higher than $80 \%$.

Catches from BGS traps also differed significantly between clusters, with mean catches ranging from 0.37 1.99 female Ae. aegypti per trap per $24 \mathrm{~h}(\mathrm{~F}=17.9 ; \mathrm{df}=5$; $\mathrm{p}<0.001)$. The maximum number of females collected per $24 \mathrm{~h}$ trapping period per cluster varied between six-17. Of all collected Ae. aegypti mosquitoes, $62.7 \%$ were females, with values in clusters ranging from $53.3-75.1 \%$ (Table I).

MQT and BGS collected a mean of 0.92 and 0.07 Ae. aegypti females, respectively, per $24 \mathrm{~h}$. Thus, daily catches were 13 times higher in BGS.

Of the total of 819 Ae. aegypti females captured in BGS traps, 798 were dissected for the determination of their parity status. The vast majority of individuals in all six clusters $(60-85.4 \%)$ were found to be in late ovarian development stages, $6.7-36 \%$ were parous and $0.9-4.7 \%$ were nulliparous (Table I).

Both traps identified cluster 1 as the area with the highest infestation of Ae. aegypti females. MQTs suggested the lowest infestation in cluster 2, whilst BGS traps identified this cluster as the third-most infested. Overall correlation between MQT and BGS, based on the lMeanAaefem dataset with one data point per cluster in each collection week, was very low (Pearson's $r=0.09$, $\mathrm{p}=0.17$ ). On cluster level, correlations were also low and not significant, with Pearson's correlation coefficients ranging between $-0.14-0.14(\mathrm{p}>0.1)$. When correlating only gravid Ae. aegypti females captured in BGS with the catches of MQTs, only slightly higher correlation indices were obtained in three clusters, but the overall correlation was lower (Pearson's $r=0.06, p=0.35$ ). However, correlation between MQT and BGS catches was significantly negative, when weekly data of all six clusters was pooled (Pearson's $\mathrm{r}=-0.38 ; \mathrm{p}=0.01$ ).

Monthly temporal pattern of adult Ae. aegypti abundance and dengue incidence - Please note that in the following analysis, the mean value of all female Ae. aegypti collected with the same trap type were pooled to yield one single data point per month. Monthly adult Ae. aegypti abundance measured by both traps varied throughout the study period. The trend was associated with the accumulated monthly precipitation. Catches in BGS traps were positively related with rainfall, revealing higher indices during the two rainy seasons. On the contrary, female catches in MQTs were highest during the dry season (Fig. 2B). 
TABLE I

Descriptive statistics of mosquitoes caught by 24 MosquiTRAPs (MQT) and 24 BG-Sentinel (BGS) traps in six areas of the neighbourhood of Cidade Nova, Manaus, state of Amazonas, Brazil, between December 2008-July 2010

\begin{tabular}{|c|c|c|c|c|c|c|c|}
\hline & Cluster 1 & Cluster 2 & Cluster 3 & Cluster 4 & Cluster 5 & Cluster 6 & Total \\
\hline \multicolumn{8}{|l|}{ MQT } \\
\hline $\mathrm{n}$ & 140 & 134 & 139 & 161 & 162 & 135 & 871 \\
\hline Mosquitoes (n) & 832 & 486 & 655 & 783 & 382 & 306 & 3,444 \\
\hline Aedes aegypti $[\mathrm{n}(\%)]$ & $290(34.9)$ & $44(9.1)$ & 189 (28.9) & $186(23.8)$ & $191(50)$ & $142(46.4)$ & $1,042(30.3)$ \\
\hline Aedes albopictus [n (\%)] & $1(0.1)$ & $39(8)$ & $38(5.8)$ & $15(1.9)$ & $12(3.1)$ & $13(4.2)$ & $118(3.4)$ \\
\hline Culex sp. [n (\%)] & $541(65)$ & $403(82.9)$ & $428(65.3)$ & $582(74.3)$ & 179 (46.9) & $151(49.3)$ & $2,284(66.3)$ \\
\hline Ae. aegypti female (n) & 241 & 18 & 101 & 185 & 187 & 135 & 867 \\
\hline Mean \pm SD & $1.72 \pm 1.93^{a}$ & $0.13 \pm 0.44^{b}$ & $0.73 \pm 0.69^{c}$ & $1.15 \pm 1.07^{a}$ & $1.15 \pm 1.31^{a}$ & $1.00 \pm 1.61^{c}$ & $0.99 \pm 1.36$ \\
\hline Maximum (n) & 13 & 3 & 2 & 6 & 9 & 9 & 13 \\
\hline Ae. aegypti female (\%) & 83.1 & 40.9 & 53.4 & 99.5 & 97.9 & 95.1 & 83.2 \\
\hline \multicolumn{8}{|l|}{ BGS } \\
\hline $\mathrm{n}$ & 143 & 150 & 148 & 160 & 154 & 153 & 908 \\
\hline Mosquitoes (n) & 1,902 & 2,981 & 5,067 & 10,075 & 745 & 1,230 & 22,000 \\
\hline Ae. aegypti $[\mathrm{n}(\%)]$ & $378(19.9)$ & $209(7)$ & $210(4.1)$ & $209(2.1)$ & $216(29)$ & $85(6.9)$ & $1,307(5.9)$ \\
\hline Ae. albopictus [n (\%)] & $3(0.2)$ & $1(0)$ & $121(2.4)$ & $5(0)$ & $8(1.1)$ & $3(0.2)$ & $141(0.6)$ \\
\hline Culex sp. [n (\%)] & $1,521(80)$ & $2,771(93)$ & $4,736(93.5)$ & $9,861(97.9)$ & $518(69.5)$ & $1,142(92.8)$ & $20,549(93.4)$ \\
\hline Ae. aegypti female (n) & 284 & 126 & 112 & 122 & 119 & 56 & 819 \\
\hline Mean \pm SD & $1.99 \pm 2.88^{a}$ & $0.84 \pm 1.37^{b}$ & $0.76 \pm 1.66 \mathrm{~b}^{c}$ & $0.76 \pm 1.52^{b}$ & $0.77 \pm 1.18^{b, c}$ & $0.37 \pm 1.36^{c}$ & $0.92 \pm 1.80$ \\
\hline Maximum (n) & 17 & 7 & 13 & 10 & 6 & 15 & 17 \\
\hline Ae. aegypti female (\%) & 75.1 & 60.3 & 53.3 & 58.4 & 55.1 & 65.9 & 62.7 \\
\hline Nulliparous [n (\%)] & $3(1.1)$ & $3(2.4)$ & $5(4.7)$ & $2(1.7)$ & $1(0.9)$ & $2(4)$ & $16(2)$ \\
\hline Parous [n (\%)] & $38(13.5)$ & $21(6.7)$ & $35(33)$ & $41(33.9)$ & $25(21.9)$ & $18(36)$ & $178(22.3)$ \\
\hline Gravid [n (\%)] & $240(85.4)$ & $102(81)$ & $66(62.3)$ & $78(64.5)$ & $88(77.2)$ & $30(60)$ & $604(75.7)$ \\
\hline
\end{tabular}

collection periods of MQT and BGS were two weeks and $24 \mathrm{~h}$, respectively. For each trap type, significant pairwise differences between the mean number of Ae. aegypti females in the six clusters are indicated by different letters (Tukey's honest significant differences, $\mathrm{p}<0.05)$. SD: standard deviation.

Dengue incidence was higher during the two rainy seasons than during the dry season (Fig. 2B). Correlation between monthly Ae. aegypti abundance in BGS traps and dengue incidence was moderate positive (Pearson's $r=0.38 ; p=0.11)$ and correlation between female abundance in MQT and dengue incidence was moderate negative (Pearson's $r=-0.31 ; p=0.20$ ). The correlation between monthly mean catches in MQTs and BGS was significantly negative (Pearson's $\mathrm{r}=-0.47 ; \mathrm{p}=0.04$ ).

Fortnightly pattern of mosquito infestation and trap positivity - For both trap types, the mean number of female Ae. aegypti collected in each monitoring week was calculated (Fig. 3A). As demonstrated before for monthly mean data, mosquito catches varied throughout the study period for both trap types, however showing different trends. Mosquito density in BGS mostly followed the pattern of rainfall, with low catch rates during the dry season. Catches were highest at the beginning and at the end of the first rainy season. After the dry period (July-November), catches increased again, but levels as high as in the first rainy season were not reached.

MQT mean catches were lowest at the beginning of the first rainy season and peaked at the beginning of the dry season. Catches remained high during the dry period, but decreased gradually until the end of the study.

Both traps were sensitive to detect the presence of female Ae. aegypti in every monitoring week during the study period. Trap positivity of BGS and MQT did not reveal differences between the dry season and the second rainy season (Fig. 3B). During the first rainy season, the dry season and the second rainy season, $44.4 \%, 56.5 \%$ and $57.8 \%$ of MQT detected the presence of females. BGS traps caught Ae. aegypti females in 50.8\%, 32.1\% and $32.1 \%$ of traps during the three seasons. In the first rainy season, the chance of trap positivity did not differ between MQT and BGS [odds ratio $(\mathrm{OR})=1.3 ; \mathrm{p}=0.13$ ]. In the dry season and second rainy season, the chance of trap positivity was significantly higher in MQTs $(\mathrm{OR}=$ 2.7; $\mathrm{p}<0.001$ and $\mathrm{OR}=2.9 ; \mathrm{p}<0.001$, respectively). The overall proportion of positive traps was $53.6 \%$ in MQT and $38.7 \%$ in BGS traps.

Effect of meteorological variables on female Ae. aegypti abundance - For the MQT data, only Ndaysrainlw was a significant meteorological predictor variable of female Ae. aegypti abundance $(\mathrm{p}<0.05)$. The final model, which included only Ndaysrain $1 w$ as explanatory variable 


\section{TABLE II}

Output of the minimal adequate linear mixed effects models of female Aedes aegypti abundance measured with MosquiTRAPs (MQT) and BG-Sentinel (BGS) in Manaus, state of Amazonas, Brazil

\begin{tabular}{|c|c|c|c|c|c|c|}
\hline Trap & Response variable & Explanatory variables & Coefficient $( \pm$ SE) & $\mathrm{t}$ & $\mathrm{df}$ & $\mathrm{p}$ \\
\hline MQT & lMeanAaefem & Ndaysrain1w & $-0.025 \pm 0.012$ & -2.14 & 239 & $<0.001$ \\
\hline \multirow[t]{2}{*}{ BGS } & IMeanAaefem & RH2w & $0.011 \pm 0.003$ & 3.38 & 232 & $<0.001$ \\
\hline & & week & $-0.005 \pm 0.001$ & -4.77 & 232 & $<0.001$ \\
\hline
\end{tabular}

df: degrees of freedom; IMeanAaefem: $\log (\mathrm{x}+10)$ - transformed mean number of Ae. aegypti females; Ndaysrain1w: number of rainy days in the week prior to mosquito sampling; $R H 2 w$ : relative humidity two weeks prior to mosquito sampling; SE: standard error.
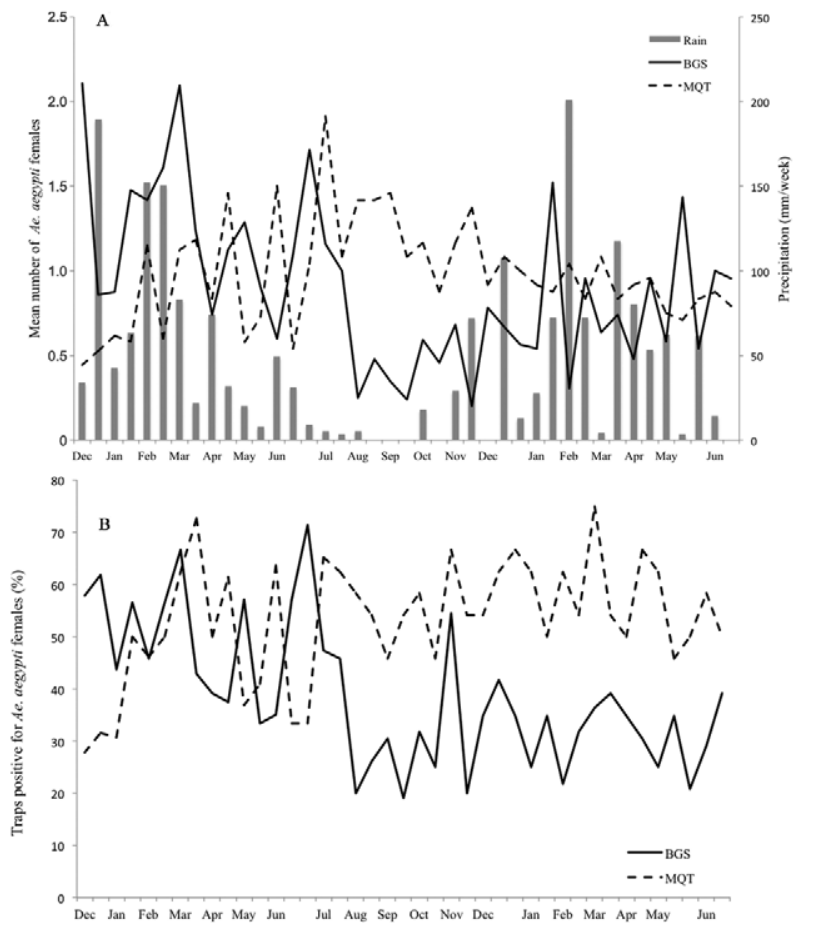

Fig. 3A: weekly precipitation and mean fortnightly catches of female Aedes aegypti in MosquiTRAP (MQT) (dashed line) and BG-Sentinel (BGS) (solid line) in Manaus, state of Amazonas, Brazil, between December 2008-June 2010; B: fortnightly trap positivity for Ae. aegypti in MQT (dashed line) and BGS (solid line) in Manaus between December 2008-June 2010.

and an AR-1 autocorrelation structure (phi = 0.52), indicates that mosquito abundance decreased with increasing accumulated rainfall during the previous week (Table II).

All meteorological variables, with exception of Raind, Rain1w, Rain3w, Rain2.3w and Tmaxd, were significant predictors of female Ae. aegypti abundance in BGS traps $(\mathrm{p}<0.05)$. Rain and humidity variables were positive predictors and temperature variables were negative predictors. The best explanatory variable was $R H 2 w$ and the final model included only the variables $R H 2 w$ and week, as other meteorological variables lost significance when used additionally to $R H 2 w$.
The final model indicates that mosquito abundance rose with increasing humidity (effect size $=0.011$ ). The variable week maintained significance, indicating that factors of non-meteorological nature affected fortnightly mosquito abundance. Table II summarises the final model, which included an AR-1 autocorrelation structure $(\mathrm{phi}=0.47)$ and a varIdent variance structure.

\section{DISCUSSION}

Both traps were designed to catch Ae. aegypti, but the vast majority of captured mosquitoes was Culex spp (predominantly $C x$. quinquefasciatus). In studies performed with MQTs in the state of Minas Gerais (MG), Brazil, Culex spp mosquitoes were less abundant than Ae. aegypti and Ae. albopictus (Gama et al. 2007, RA Gama, unpublished observations, de Resende et al. 2013), suggesting that the MQT is highly specific for dengue vectors. Honório et al. (2009) used MQTs and collected 85\% of non-Aedes mosquitoes (also mainly Cx. quinquefasciatus) in a suburban slum, but only $12 \%$ in an urban and $24 \%$ in a suburban neighbourhood of the city of Rio de Janeiro, Brazil. High numbers of $C x$. quinquefasciatus have been previously observed in BGS traps in Rio de Janeiro and in San Juan, Puerto Rico (Maciel-de-Freitas et al. 2006, Barrera et al. 2011). In Belo Horizonte, the capital of $\mathrm{MG}$, on the other hand, $C x$. quinquefasciatus was rare in BGS traps, as well as in other adult mosquito traps, which were evaluated simultaneously (Kröckel et al. 2006). In Australia, BGS collected predominantly $A e$. aegypti (Williams et al. 2006). We therefore expect, that the high Culex catches do not reflect higher attraction of this genus to both, MQT and BGS traps, but a much higher abundance of this genus in Cidade Nova.

As $C x$. quinquefasciatus is the primary vector of bancroftian filariasis in Brazil (Rachou 1956, Rocha \& Fontes 1998), its high abundance raises concern about the disease. Bancroftian filariasis was present in Manaus in the 1950s (Rocha \& Fontes 1998) and, nowadays, transmission occurs in Recife, the capital state of Pernambuco (MS/SVS 2009). Possibly, both evaluated traps might be used as monitoring tools for $C x$. quinquefasciatus in urban areas of Brazil. Aspirators have been usually used in Brazil to detect Wuchereria bancrofti infections in Cx. quinquefasciatus (Medeiros et al. 1992, Fontes et al. 2012, Korte et al. 2013). To catch the filariasis vectors through aspiration, it is necessary to have access to 
households during the nocturnal period. The use of traps would therefore be more convenient for both residents and health agents.

Cx. quinquefasciatus is also a competent vector of West Nile virus (WNV) (Goddard et al. 2002, Micieli et al. 2013). Recent studies found neutralising antibodies to WNV in horses and chicken from the Brazilian Pantanal (Pauvolid-Corrêa et al. 2011, 2014, Melandri et al. 2012, Ometto et al. 2013), however no viral genome was detected in mosquitoes (Pauvolid-Corrêa et al. 2011) and the vector capacity of Brazilian Cx. quinquefasciatus strains is unclear. As WNV was previously detected in mosquitoes that were captured with BGS (Farajollahi et al. 2009), this trap appears to be suitable for field studies that intent to examine the role of mosquitoes in WNV transmission in Brazil.

Both traps found Ae. aegypti to be the second-most abundant and Ae. albopictus the third-most abundant species in the study area. Considering only these two species, MQT and BGS caught about the same percentage of Ae aegypti (89.9\% in MQT and $90.2 \%$ in BGS). This result is similar to observations from an ovitrap survey from Manaus in 2004, where $85.5 \%$ and $14.5 \%$ of larvae hatched from collected eggs were Ae. aegypti and Ae.albopictus, respectively (Ríos-Velásquez et al. 2007). Ae. aegypti populations decreased in North America with the establishment of Ae. albopictus (O'Meara et al. 1995). Despite the fact, that Ae. albopictus is a superior larval competitor, both coexist and in some North American settings, Ae. aegypti still remains dominant [reviewed by Juliano and Lounibos (2005)]. It was demonstrated under field conditions, that Ae. albopictus is also a superior larval competitor in Brazil (Braks et al. 2004). When comparing our result concerning percentages of Ae. aegypti and Ae. albopictus with the results of Ríos-Velásquez et al. (2007), based on data collected about four years before, it seems that the relative abundance of Ae. albopictus did not increase. One must however consider that the studies were conducted with different trapping devices in different neighbourhoods of Manaus.

Ae. aegypti monitoring results in the six clusters of Cidade Nova showed that the two traps did not result in the same infestation rankings and that correlations between mosquito collections in the two traps were low. This difference might be associated with the MQT's characteristic to attract mainly gravid Ae. aegypti females (Fávaro et al. 2006), whilst the BGS attracts females in different physiological stages (Maciel-de-Freitas et al. 2006, Williams et al. 2006, Rapley et al. 2009, Ball \& Ritchie 2010). In the present work, we also collected females in different physiological stages. As observed before in Australia (Rapley et al. 2009), we collected predominantly females in advanced ovarian development stages ( $>$ Christopher's stage II), but we do not know how many of these females were ready to lay eggs. Another explanation for lack of correlation on cluster level could lie in the study protocol: BGS traps changed their position every week, whilst MQT were located on fixed positions. Furthermore, MQTs were exposed continuously for two weeks, whilst catch bags from BGS were removed after a sampling period of $24 \mathrm{~h}$. BGS catches might have been strongly affected by the rainfall during the short sampling period, in a way that strong rains diminished the mosquitoes' flight activity. This hypothesis was not supported, as rainfall of the sampling day was no significant predictor of female Ae. aegypti abundance.

Interestingly, the overall mean numbers of Ae. aegyp$t i$ females collected in the two traps were similar. However, the BGS traps collected 0.92 females in $24 \mathrm{~h}$, whilst MQTs collected 0.99 females during a trapping period of two weeks, which is an equivalent of 0.07 individuals in $24 \mathrm{~h}$. Daily catch rates of BGS traps were therefore about 13 times higher. This difference is probably due to (i) the trap-operating type: the BGS is active and ventilates even those mosquitoes inside the trap, who come close to the black catching funnel, whilst the MQT is a passive device that catches only those mosquitoes who actively enter the trap and land on the sticky card; (ii) the attractive size of the trap surface: the surface area of the BGS is approximately five times bigger.

MQT catches were highest during the dry season and numbers of mosquitoes in BGS increased in the rainy season. The observed temporal pattern of female $A e$. aegypti in MQTs was contrary to the findings of other longitudinal studies with duration of at least one year, which were conducted in several cities of MG (Eiras \& Resende 2009), in Belo Horizonte (Melo et al. 2012) and in Rio de Janeiro (Honório et al. 2009). In all these studies, MQT catches were higher in the rainy season. In the Brazilian state of Sergipe, on the other hand, catches of female Ae. aegypti were higher during the dry season, which the authors explained to have happened because of extensive application of vector control (Steffler et al. 2011). In our study, the increased MQT catches in the dry season were probably caused by a reduction of breeding sites, confirmed by a lower house index and Breteau index during the dry season in Cidade Nova (FVS-AM). In this way, fewer breeding sites were competing with MQTs to attract gravid mosquitoes, presumably leading to increased catch rates. Ae. aegypti females are known to lay their eggs in multiple containers, a behaviour that is referred to as "skip oviposition" [reviewed by Reiter (2007)]. A general reduction in the number of breeding sites might also have forced females to retain eggs and disperse farer to seek oviposition sites. In this way, the increased number of females in MQTs during the dry season might reflect higher dispersal of gravid females. It was shown before, that gravid Ae. aegypti disperse more, when no breeding sites are available (Edman et al. 1998). Additional investigations are necessary to characterise longitudinal data obtained by BGS and MQT in different geographic and climatic regions.

As a high percentage of females caught in BGS traps were in late ovarian development stages, a similar longitudinal trend as observed for MQT could have been possible. As this did not happen, we presume that most of the females that were classified as "late ovarian development stages" were not ready yet for oviposition, but were seeking for a host in order to complete egg maturation. Another observation from our study, which strengthens this argument, is that correlation coefficients between catches in MQT and BGS did not increase substantially, 
when only mosquitoes from late ovarian development stages in BGS were considered for the correlation analysis. Multiple blood feeding is well documented for Ae. aegypti (Scott et al. 1993a, b, 2000).

Monthly female Ae. aegypti abundance in BGS traps was positively associated with dengue incidence, whilst dengue vector abundance in MQTs was negatively associated with dengue incidence. The pattern of BGS catches and dengue incidence being positively associated with rainfall was observed before in Puerto Rico (Barrera et al. 2011).

Of all 28 tested meteorological variables, only Ndaysrain $1 w$ was a significant predictor of female Ae. aegypti abundance in MQTs (in a negative relationship). It was expectable, that temperature variables were poor predictors, as variation throughout the year was low. It is however surprising, that none of the Rain or $R H$ variables were significant. All rain variables were negatively associated with mosquito abundance at all evaluated time lags. With increasing number of rainy days during the traps' exposal time in the field, the availability of breeding sites increased, as many suitable objects were available in the yards. Therefore, the MQT had to compete with more recipients for gravid females, which presumably lead to a reduction in the number of collected mosquitoes in rainy periods. Another explanation of the result could be an inhibition of oviposition behaviour on rainy days, a phenomenon that has been observed by P Reiter and MA Amador [cited as unpublished observations in Reiter (2007)]. Honório et al. (2009) found a negative effect of rainfall at lag 1 on MQT collections in one of three neighbourhoods of Rio de Janeiro. Apparently, this neighbourhood had similar characteristics to our study site, with houses and yards, permanent water containers and rain-dependent breeding sites. In contrast to our study however, rainfall at other lags was positively associated with female abundance (Honório et al. 2009). In a study of 12 weeks duration, conducted during the rainy season in Pedro Leopoldo, MG, a negative relationship between MQT catches and rainfall was observed (de Resende et al. 2013).

Most meteorological variables were significant predictors of female Ae. aegypti abundance in BGS. Rain and humidity variables were positively associated with mosquito abundance, no negative association was found after rain (accumulated rain or number of rainy days) has reached a certain threshold. This result is in concordance with results from a simulation study, which revealed that Ae. aegypti larvae and pupae are almost not affected by flushing effects due to heavy rain (Koenraadt \& Harrington 2008). The best predictor of mosquito abundance in the LME model was the mean RH at two weeks before the $24 \mathrm{~h}$ trapping period. Humidity at the same time lag was also significantly associated with female abundance in BGS traps in Cairns, Australia (Azil et al. 2010).

Minimum temperature was a significant negative predictor on the trapping day (range of daily minima: 22$27.5^{\circ} \mathrm{C}$ ) and for lag 3 weeks. All maximum temperature variables (range of daily maxima: $27.3-37.6^{\circ} \mathrm{C}$ ) were also negatively associated with mosquito collections. According to Beserra et al. (2006), the ideal temperature range for Ae. aegypti in terms of development, longevity and fe- cundity is $22-29^{\circ} \mathrm{C}$ and Rueda et al. (1990) found the ideal temperature in terms of survival to adult stage to range between $20-27^{\circ} \mathrm{C}$. The lower temperature threshold was not reached in Manaus during our study period. The upper ideal temperature however was frequently exceeded. During those periods of high temperatures, mosquitoes likely reduced their flight activities and sought for shadowed places in order to avoid excessive heat. This probably contributed to decreased collections in BGS traps. Furthermore, highest temperatures occurred during the dry season (Fig. 1), at a time, when the overall number of breeding sites was reduced. At that time, oviposition in existing containers probably increased. Mendki et al. (2000) reported the oviposition-stimulating effect of a semiochemical of conspecific larvae on Ae. aegypti. In a recent field study, the number of eggs laid per recipient increased with increasing conspecific larval density and in the same study, the wing size of mosquitoes decreased with increasing larval density (Wong et al. 2011). If the same has happened in our study, it is possible that during the dry and hot season the mosquitoes' body size decreased, which might have led to reduced biting persistence (Nasci 1991), reduced fecundity (Farjana \& Tuno 2012) and decreased mating capacity of males (Ponlawat \& Harrington 2009), factors that may have contributed to a reduction of the female mosquito population. It would therefore be interesting to assess mosquito body size in future longitudinal studies with adult traps.

In summary we demonstrated that MQT and BGS detected the same relative abundance of Ae. aegypti, Ae. albopictus and Culex spp in Manaus. Both traps detected the presence of Ae. aegypti in Cidade Nova at all monitoring weeks, which shows that MQT and BGS are sensitive tools for dengue vector monitoring. However, the daily catch rate of female dengue vectors was 13 times higher in the BGS. Quantitative longitudinal data of both traps were more suitable than presence/absence data to detect seasonal differences in mosquito abundance. Time series of fortnightly female Ae. aegypti collections in MQT and BGS followed opposing trends. The MQT collected highest numbers of female dengue vectors during the dry season, the period when collections in BGS reached their lowest level. It appears that the MQT is especially sensitive to collect gravid Ae. aegypti in the dry season of the Amazonian region. Catches of BGS traps however reflected better the dynamic of dengue incidence.

\section{ACKNOWLEDGEMENTS}

To all inhabitants of Cidade Nova who participated in the study, to all contributors from the FVS, namely Luzia Mustáfa, Ricardo Passos, Wanderson Sampaio and all field workers, and to the Entomology Department of the FMT-HVD, under supervision of Maria das Graças Vale Barbosa and Nelson Ferreira Fé, for assistance in processing the BGS catch bags that returned from the field.

\section{REFERENCES}

Azil AH, Long SA, Ritchie SA, Williams CR 2010. The development of predictive tools for pre-emptive dengue vector control: a study of Aedes aegypti abundance and meteorological variables in North Queensland, Australia. Trop Med Int Health 15: 1190-1197. 
Ball TS, Ritchie SR 2010. Sampling biases of the BG-Sentinel trap with respect to physiology, age and body size of adult Aedes aegypti (Diptera: Culicidae). J Med Entomol 47: 649-656.

Barrera R, Amador M, MacKay AJ 2011. Population dynamics of Aedes aegypti and dengue as influenced by weather and human behavior in San Juan, Puerto Rico. PLoS Negl Trop Dis 5: e1378.

Bastos MS, Figueiredo RM, Ramasawmy R, Itapirema E, Gimaque JB, Santos LO, Figueiredo LT, Mourão MP 2012. Simultaneous circulation of all four dengue serotypes in Manaus, state of Amazonas, Brazil in 2011. Rev Soc Bras Med Trop 45: 393-394.

Beserra EB, Castro FPJ, dos Santos JW, Santos TS, Fernandes CR 2006. Biologia e exigências térmicas de Aedes aegypti (L.) (Diptera: Culicidae) provenientes de quatro regiões bioclimáticas da Paraíba. Neotrop Entomol 35: 853-860.

Braks MAH, Honório NA, Lounibos LP, Lourenço-de-Oliveira R, Juliano SA 2004. Interspecific competition between two invasive species of container mosquitoes, Aedes aegypti and Aedes albopictus (Diptera: Culicidae), in Brazil. Ann Entomol Soc Am 97: 130-139.

Chadee DD, Shivnauth B, Rawlins SC, Chen AA 2007. Climate, mosquito indices and the epidemiology of dengue fever in Trinidad (2002-2004). Ann Trop Med Parasitol 101: 69-77.

Christophers SR 1960. Aedes aegypti (L.). The yellow fever mosquito - its life history, bionomics and structure, Cambridge University Press, Cambridge, 739 pp.

de Resende MC, Silva IM, Ellis BR, Eiras AE 2013. A comparison of larval, ovitrap and MosquiTRAP surveillance for Aedes (Stegomyia) aegypti. Mem Inst Oswaldo Cruz 108: 1024-1030.

Descloux E, Mangea M, Menkes CE, Lengaigne M, Leroy A, Tehei T, Guillaumot L, Teurlai M, Gourinat AC, Benzler J, Pfannstiel A, Grangeon JP, Degallier N, de Lamballerie X 2012. Climatebased models for understanding and forecasting dengue epidemics. PLoS Negl Trop Dis 6: e1470.

Detinova TS 1962. Age-grouping methods in Diptera of medical importance with special reference to some vectors of malaria. Monogr Ser World Health Organ 47: 13-191.

Edman JD, Scott TW, Costero A, Morrison AC, Harrington LC, Clark GG 1998. Aedes aegypti (Diptera: Culicidae) movement influenced by availability of oviposition sites. $J$ Med Entomol 35: 578-583.

Eiras AE, Resende MC 2009. Preliminary evaluation of the 'DengueMI' technology for Aedes aegypti monitoring and control. Cad Saude Publica 25 (Suppl. 1): S45-S58.

Farajollahi A, Kesavaraju B, Price DC, Williams GM, Healy SP, Gaugler R, Nelder MP 2009. Field efficacy of BG-Sentinel and industry-standard traps for Aedes albopictus (Diptera: Culicidae) and West Nile virus surveillance. J Med Entomol 46: 919-925.

Farjana T, Tuno N 2012. Effect of body size on multiple blood feeding and egg retention of Aedes aegypti (L.) and Aedes albopictus (Skuse) (Diptera: Culicidae). Eisei Dobutsu 63: 123-131.

Farnesi LC, Martins AJ, Valle D, Rezende GL 2009. Embryonic development of Aedes aegypti (Diptera: Culicidae): influence of different constant temperatures. Mem Inst Oswaldo Cruz 104: 124-126.

Fávaro EA, Dibo MR, Mondini A, Ferreira AC, Barbosa AA, Eiras AE, Barata EA, Chiaravalloti-Neto F 2006. Physiological state of $\mathrm{Ae-}$ des (Stegomyia) aegypti mosquitoes captured with MosquiTRAPs in Mirassol, São Paulo, Brazil. J Vector Ecol 31: 285-291.

Fay RW, Eliason DA 1966. A preferred oviposition site as a surveillance method for Aedes aegypti. Mosq News 26: 531-535.

Figueiredo ML, Alfonso HL, Amarilla AA, Figueiredo LT, Aquino VH, Costa CA, Luz SL 2013a. Detection of DENV-4 genotype I from mosquitoes collected in the city of Manaus, Brazil. Virol J 10: 60.
Figueiredo RM, Mourão MP, Abi-Abib YE, Oliveira CM, Roque R, Azara T, Ohly J, Degener C, Geier M, Eiras AE 2013b. Identification of dengue viruses in naturally infected Aedes aegypti females captured with BioGents (BG)-Sentinel traps in Manaus, Amazonas, Brazil. Rev Soc Bras Med Trop 46: 60.

Figueiredo RM, Naveca FG, Bastos MS, Melo MN, Viana SS, Mourão MP, Costa CA, Farias IP 2008. Dengue virus type 4, Manaus, Brazil. Emerg Infect Dis 14: 667-669.

Figueiredo RM, Thatcher BD, Lima ML, Almeida TC, Alecrim WD, Guerra MV 2004. Doenças exantemáticas e primeira epidemia de dengue ocorrida em Manaus, Amazonas, no período de 19981999. Rev Soc Bras Med Trop 37: 476-479.

Focks DA 2003. A review of entomological sampling methods and indicators for dengue vectors, Special Programme for Research and Training in Tropical Diseases (TDR), UNICEF/UNDP/World Bank/WHO, Gainsville, 38 pp.

Fontes G, Leite AB, Lima AR, Freitas H, Ehrenberg JP, Rocha EM 2012. Lymphatic filariasis in Brazil: epidemiological situation and outlook for elimination. Parasit Vectors 5: 272.

Gama RA, Silva EM, Silva IM, Resende MC, Eiras AE 2007. Evaluation of the sticky MosquiTRAP for detecting Aedes (Stegomyia) aegypti (L.) (Diptera: Culicidae) during the dry season in Belo Horizonte, Minas Gerais, Brazil. Neotrop Entomol 36: 294-302.

Goddard LB, Roth AE, Reisen WK, Scott TW 2002. Vector competence of California mosquitoes for West Nile virus. Emerg Infect Dis 8: 1385-1391.

Honório NA, Codeço CT, Alves FC, Magalhães MA, Lourenço-deOliveira R 2009. Temporal distribution of Aedes aegypti in different districts of Rio de Janeiro, Brazil, measured by two types of traps. J Med Entomol 46: 1001-1014.

IBGE - Instituto Brasileiro de Geografia e Estatística 2011. Censo 2010. Informações sobre bairros segundo os municípios. Available from: ibge.gov.br/home/presidencia/noticias/imprensa/ppts/ 0000000488.xls.

Juliano SA, Lounibos LP 2005. Ecology of invasive mosquitoes: effects on resident species and on human health. Ecol Lett 8: 558-574.

Koenraadt CJ, Harrington LC 2008. Flushing effect of rain on container-inhabiting mosquitoes Aedes aegypti and Culex pipiens (Diptera: Culicidae). J Med Entomol 45: 28-35.

Korte RL, Fontes G, Camargo JS, Rocha EM, Araujo EA, Oliveira MZ, Santos RV, Camargo LM 2013. Survey of bancroftian filariasis infection in humans and Culex mosquitoes in the western Brazilian Amazon Region: implications for transmission and control. Rev Soc Bras Med Trop 46: 214-220.

Kröckel U, Rose A, Eiras AE, Geier M 2006. New tools for surveillance of adult yellow fever mosquitoes: comparison of trap catches with human landing rates in an urban environment. $J$ Am Mosq Control Assoc 22: 229-238.

Maciel-de-Freitas R, Eiras AE, Lourenço-de-Oliveira R 2006. Field evaluation of effectiveness of the BG-Sentinel, a new trap for capturing adult Aedes aegypti (Diptera: Culicidae). Mem Inst Oswaldo Cruz 101: 321-325.

Medeiros Z, Dreyer G, Andrade LD, Pires ML, Mendes J, Pimentel R 1992. Wuchereria bancrofti microfilarial density of autochthonous cases and natural Culex infectivity rates in Northeast Brazil. J Trop Med Hyg 95: 214-217.

Meeraus WH, Armistead JS, Arias JR 2008. Field comparison of novel and gold standard traps for collecting Aedes albopictus in northern Virginia. J Am Mosq Control Assoc 24: 244-248.

Melandri V, Guimarães AE, Komar N, Nogueira ML, Mondini A, Fernandez-Sesma A, Alencar J, Bosch I 2012. Serological detec- 
tion of West Nile virus in horses and chicken from Pantanal, Brazil. Mem Inst Oswaldo Cruz 107: 1073-1075.

Melo DP, Scherrer LR, Eiras AE 2012. Dengue fever occurrence and vector detection by larval survey, ovitrap and MosquiTRAP: a space-time clusters analysis. PLOS ONE 7: e42125.

Mendki MJ, Ganesan K, Prakash S, Suryanarayana MVS, Malhotra RC, Vaidyanathaswamy R 2000. Heneicosane: an ovipositionattractant pheromone of larval origin in Aedes aegypti mosquito. Curr Sci 78: 1295-1296.

Micieli MV, Matacchiero AC, Muttis E, Fonseca DM, Aliota MT, Kramer LD 2013. Vector competence of Argentine mosquitoes (Diptera: Culicidae) for West Nile virus (Flaviviridae: Flavivirus). J Med Entomol 50: 853-862.

Mogi M, Khamboonruang C, Choochote W, Suwanpanit P 1988. Ovitrap surveys of dengue vector mosquitoes in Chiang Mai, northern Thailand: seasonal shifts in relative abundance of Aedes albopictus and Ae. aegypti. Med Vet Entomol 2: 319-324.

MS/SVS - Ministério da Saúde/Secretaria de Vigilância em Saúde 2005. Guia de vigilância epidemiológica, Série A, Normas e Manuais Técnicos, 6th ed., MS/SVS, Brasília, 816 pp.

MS/SVS - Ministério da Saúde/Secretaria de Vigilância em Saúde 2009. Guia de vigilância epidemiológica e eliminação da filariose linfática, MS/SVS, Brasília, 80 pp.

Nasci RS 1991. Influence of larval and adult nutrition on biting persistence in Aedes aegypti (Diptera: Culicidae). J Med Entomol 28: $522-526$

Nogueira RMR, Eppinghaus ALF 2011. Dengue virus type 4 arrives in the state of Rio de Janeiro: a challenge for epidemiological surveillance and control. Mem Inst Oswaldo Cruz 106: 255-256.

O'Meara GF, Evans LFJ, Gettman AD, Cuda JP 1995. Spread of Aedes albopictus and decline of Ae. aegypti (Diptera: Culicidae) i n Florida. J Med Entomol 32: 554-562.

Ometto T, Durigon EL, Araujo J, Aprelon R, Aguiar DM, Cavalcante GT, Melo RM, Levi JE, Azevedo Jr SM, Petry MV, Neto IS, Serafini P, Villalobos E, Cunha EM, Lara MCCSH, Nava AFD, Nardi MS, Hurtado R, Rodrigues R, Sherer AL, Sherer JFM, Geraldi MP, Seixas MMM, Peterka C, Bandeira DS, Pradel J, Vachiery N, Labruna MB, Camargo LM, Lanciotti R, Lefrancois T 2013. West Nile virus surveillance, Brazil, 2008-2010. Trans R Soc Trop Med Hyg 107: 723-730.

Pauvolid-Corrêa A, Campos Z, Juliano R, Velez J, Nogueira RM, Komar N 2014. Serological evidence of widespread circulation of West Nile virus and other flaviviruses in equines of the Pantanal, Brazil. PLoS Negl Trop Dis 8: e2706.

Pauvolid-Corrêa A, Morales MA, Levis S, Figueiredo LTM, Couto-Lima D, Campos Z, Nogueira MF, da Silva EE, Nogueira RMR, Schatzmayr HG 2011. Neutralising antibodies for West Nile virus in horses from Brazilian Pantanal. Mem Inst Oswaldo Cruz 106: 467-474.

Pinheiro J, Bates D, DebRoy S, Sarkar D, R Development Core Team 2011. nlme: linear and nonlinear mixed effects models. R package v.3.1-98. Available from: CRAN.R-project.org/package=nlme.

Pinheiro JC, Bates DM 2000. Mixed-effects models in S and S-PLUS, Springer, New York, 528 pp.

Ponlawat A, Harrington LC 2009. Factors associated with male mating success of the dengue vector mosquito, Aedes aegypti. Am J Trop Med Hyg 80: 395-400.

R Development Core Team 2011. R: a language and environment for statistical computing. Available from: R-project.org/.

Rachou RG 1956. Transmissores da filariose bancroftiana no Brasil. Rev Bras Malariol Doencas Trop 8: 267-279.
Rapley LP, Johnson PH, Williams CR, Silcock RM, Larkman M, Long SA, Russell RC, Ritchie SA 2009. A lethal ovitrap-based mass trapping scheme for dengue control in Australia: II. Impact on populations of the mosquito Aedes aegypti. Med Vet Entomol 23: 303-316.

Reiter P 2007. Oviposition, dispersal and survival in Aedes aegypti: implications for the efficacy of control strategies: Vector Borne Zoonotic Dis 7: 261-273.

Reiter P, Amador MA, Colon N 1991. Enhancement of the CDC ovitrap with hay infusions for daily monitoring of Aedes aegypti populations. J Am Mosq Control Assoc 7: 52-55.

Ríos-Velásquez CM, Codeço CT, Honório NA, Sabroza PS, Moresco M, Cunha ICL, Levino A, Toledo LM, Luz SLB 2007. Distribution of dengue vectors in neighborhoods with different urbanization types of Manaus, state of Amazonas, Brazil. Mem Inst Oswaldo Cruz 102: 617-623.

Ritchie SA, Long S, Hart A, Webb CE, Russell RC 2003. An adulticidal sticky ovitrap for sampling container-breeding mosquitoes. J Am Mosq Control Assoc 19: 235-242.

Ritchie SA, Long S, Smith G, Pyke A, Knox TB 2004. Entomological investigations in a focus of dengue transmission in Cairns, Queensland, Australia, by using the sticky ovitraps. $J$ Med Entomol 41: 1-4.

Rocha EM, Fontes G 1998. Filariose bancroftiana no Brasil. Rev Saude Publica 32: 98-105.

Rueda LM, Patel KJ, Axtell RC, Stinner RE 1990. Temperature-dependent development and survival rates of Culex quinquefasciatus and Aedes aegypti (Diptera: Culicidae). J Med Entomol 27: 892-898.

San Martin JL, Brathwaite O, Zambrano B, Solorzano JO, Bouckenooghe A, Dayan GH, Guzman MG 2010. The epidemiology of dengue in the Americas over the last three decades: a worrisome reality. Am J Trop Med Hyg 82: 128-135.

Scott TW, Amerasinghe PH, Morrison AC, Lorenz LH, Clark GG, Strickman D, Kittayapong P, Edman JD 2000. Longitudinal studies of Aedes aegypti (Diptera: Culicidae) in Thailand and Puerto Rico: blood feeding frequency. J Med Entomol 37: 89-101.

Scott TW, Chow E, Strickman D, Kittayapong P, Wirtz RA, Lorenz LH, Edman JD 1993a. Blood-feeding patterns of Aedes aegyp$t i$ (Diptera: Culicidae) collected in a rural Thai village. $J$ Med Entomol 30: 922-927.

Scott TW, Clark GG, Lorenz LH, Amerasinghe PH, Reiter P, Edman JD 1993b. Detection of multiple blood feeding in Aedes aegypti (Diptera: Culicidae) during a single gonotrophic cycle using a histologic technique. J Med Entomol 30: 94-99.

Steffler LM, Marteis LS, Dolabella SS, Cavalcanti SCH, dos Santos RLC 2011. Risk of dengue occurrence based on the capture of gravid Aedes aegypti females using MosquiTRAP. Mem Inst Oswaldo Cruz 106: 365-367.

Teixeira MG 2012. Few characteristics of dengue's fever epidemiology in Brazil. Rev Inst Med Trop Sao Paulo 54 (Suppl. 18): S1-S4.

Vezzani D, Velázquez SM, Schweigmann N 2004. Seasonal pattern of abundance of Aedes aegypti (Diptera: Culicidae) in Buenos Aires city, Argentina. Mem Inst Oswaldo Cruz 99: 351-356.

Watts DM, Burke DS, Harrison BA, Whitmire RE, Nisalak A 1987. Effect of temperature on the vector efficiency of Aedes aegypti for dengue 2 virus. Am J Trop Med Hyg 36: 143-152.

Williams CR, Long SA, Russell RC, Ritchie SA 2006. Field efficacy of the BG-Sentinel compared with CDC Backpack Aspirators and $\mathrm{CO}_{2}$-baited EVS traps for collection of adult Aedes aegypti in Cairns, Queensland, Australia. J Am Mosq Control Assoc 22: 296-300. 
Williams CR, Long SA, Webb CE, Bitzhenner M, Geier M, Russell RC, Ritchie SA 2007. Aedes aegypti population sampling using BG-Sentinel traps in North Queensland Australia: statistical considerations for trap deployment and sampling strategy. $J$ Med Entomol 44: 345-350.

Wong J, Stoddard ST, Astete H, Morrison AC, Scott TW 2011. Oviposition site selection by the dengue vector Aedes aegypti and its implications for dengue control. PLoS Negl Trop Dis 5: e1015.
Wood S 2006. Generalized additive models: an introduction with $R$, Chapman and Hall/CRC, Boca Raton, 384 pp.

Zar JH 2010. Biostatistical analysis, Prentice Hall, Upper Saddle River, 944 pp.

Zuur AF, Ieno EN, Walker NJ, Saveliev AA, Smith GM 2009. Mixed effects models and extensions in ecology with $R$, Springer, New York, 600 pp. 